\title{
Blood lipid variability in relation to relative weight and biochemical markers of tobacco and alcohol consumption
}

\author{
L. Janzon, J. Franzén, S.-E. Lindell and E. Trell \\ Department of Community Medicine, University of Lund, Malmö General Hospital, S-214 01 Malmö, Sweden.
}

\begin{abstract}
Summary: Carboxyhaemoglobin (COHb\%) and gamma-glutamyl-transferase (GGT) are today frequently used as objective indicators of tobacco and alcohol consumption. The relationships between $\mathrm{COHb} \%$, GGT and relative body weight, cholesterol, triglyceride and apolipoprotein AI (Apo-AI) were studied in middle-aged men attending a preventive medical programme in Malmö, Sweden. Although statistically significant the influence of $\mathrm{COHb} \%$ on cholesterol and triglyceride was found to be clinically insignificant. GGT and body weight had, independent of each other, a significant influence on cholesterol and triglyceride. GGT was found to have a positive correlation to Apo-AI whereas body weight was found to have a negative correlation to Apo-AI. Four per cent of the cholesterol variability, $16 \%$ of the triglyceride variability and about $10 \%$ of the variability in Apo-AI could, in this study, be accounted for by $\mathrm{COHb} \%$, GGT and relative body weight.
\end{abstract}

\section{Introduction}

In order to improve the precision with which we measure blood lipids it is important to control as many different external sources of variation as possible. This is especially important in studies where the efficiency of different lipid lowering treatments are evaluated. Although results from previous studies of the influence of smoking (Dales et al., 1974; Goldbourt \& Medalie, 1977), alcohol (Ostrander et al., 1974; Danielsson et al., 1978) and body weight (Albrink \& Meigs, 1964) on blood lipids have not been unequivocal, it seems as if at least heavy smoking, heavy drinking and obesity, respectively, are associated with increased serum levels of cholesterol and/or triglycerides. Published studies give no estimate, however, of how much of the blood lipid variability can be accounted for by smoking, drinking and body weight.

It is a common experience that it is difficult to obtain a reliable history of smoking and drinking habits. For this reason, carboxyhaemoglobin (COHb\%) and gamma-glutamyl-transferase (GGT) are frequently used as objective indicators of tobacco and alcohol consumption, respectively, and have as such been found to be useful at least to characterize groups of individuals (Janzon et al., 1981; Whitehead et al., 1978).

The aim of the present study was to assess the relationships between $\mathrm{COHb} \%$, GGT and body weight, and cholesterol, triglyceride and

Correspondence: L. Janzon, M.D.

Accepted: 1 November 1984 apolipoprotein AI (Apo-AI), and to assess how much of the lipid variability can be accounted for by the first three factors.

\section{Materials and methods}

From November 1974, consecutive middle-aged birth year cohorts in Malmö, Sweden have been invited to a health screening and intervention programme at the Department of Preventive Medicine, Malmö General Hospital. The details of the programme have been given elsewhere (Peterson et al., 1980). The participation rate is about $75 \%$. For the present study, a random sample of 1,035 participants, born 1930-1931 and screened 1978-1979, was analysed.

All tests were obtained during the forenoon with the subjects in fasting and non-smoking state. Fasting and non-smoking prior to the tests was confirmed by questioning.

\section{Gamma-glutamyl-transferase}

GGT was measured according to the recommendations of the Scandinavian enzyme committee (Wahlefeldt, 1974).

\section{Carboxyhaemoglobin}

$\mathrm{COHb} \%$ was analysed in venous blood according to the method described by Collison et al. (1968).

(C) The Fellowship of Postgraduate Medicine, 1985 
Table I Correlation between $\mathrm{COHb} \%, \mathrm{~A} / \mathrm{I}$ weight, GGT and cholesterol, triglyceride and Apo-AI. Partial correlation coefficients, $r$, are given.

\begin{tabular}{lccccrr}
\hline & \multicolumn{2}{c}{ Cholesterol } & \multicolumn{2}{c}{ Triglyceride } & \multicolumn{2}{c}{ Apo-AI } \\
& $\mathrm{r}$ & $\boldsymbol{P}$ & $\mathrm{r}$ & $\boldsymbol{P}$ & $\mathrm{r}$ & $\boldsymbol{P}$ \\
\hline COHb\% $^{\mathrm{a}}$ & 0.08 & $<0.05$ & 0.1 & $<0.05$ & -0.09 & \\
A/I weight $^{\mathrm{b}}$ & 0.13 & $<0.001$ & 0.29 & $<0.001$ & $-0.23<0.001$ \\
GGT $^{\mathrm{c}}$ & 0.11 & $<0.001$ & 0.23 & $<0.001$ & $0.29<0.001$
\end{tabular}

a: controlling for A/I weight and GGT; b: controlling for $\mathrm{COHb} \%$ and GGT; c: controlling for $\mathrm{COHb} \%$ and $\mathrm{A} / \mathrm{I}$ weight.

Body weight

Body weight was expressed as actual/ideal (A/I) weight (Lindeberg et al., 1956).

\section{Cholesterol and triglyceride}

Cholesterol and triglyceride in plasma were determined according to standard methods (Roeschlav et al., 1974; Wahlefeldt, 1974).

\section{Apolipoprotein AI}

Apo-AI was determined by electro-immunodiffusion (Laurell, 1965). This analysis was only done in a randomly selected subgroup of 400 subjects.

\section{Statistical methods}

The computer program BMDP7D was used for the statistical analysis (Biomedical Computer Program, 1981). Partial correlation coefficients were used to express the association between $\mathrm{COHb} \%$, GGT and A/I weight, respectively, and cholesterol, triglyceride and Apo-AI. In these analyses the influence of each factor was assessed after adjustment for differences in the remaining two. Multiple stepwise correlation was used to assess the degree of association between $\mathrm{COHb} \%+\mathrm{A} / \mathrm{I}$ weight + GGT and cholesterol, triglyceride and Apo-AI. The multiple $\mathrm{r}^{2}$ was used to assess how much of the variability in cholesterol, triglyceride and Apo-AI could be accounted for by these three factors. The degree of lipid variability accounted for by $\mathrm{COHb} \%$, GGT and A/I weight was also assessed by analysis of variance. For this we divided the distribution of $\mathrm{COHb} \%$, GGT and A/I weight respectively in quintiles. Mean values and variances for cholesterol, triglyceride and Apo-AI were calculated for each of these quintiles. Blood lipido variability was not uniform in these quintiles. For the one-way analysis of variance we therefore used the Brown-Forsythe test statistic (Brown \& Forsythe, 1974) which does not assume the within group variances to be equal.

\section{Results}

The partial correlation coefficients between $\mathrm{COHb} \%$, A/I weight and GGT, respectively, and blood lipids are shown in Table I. COHb\%, A/I weight and GGT were all found to have a positive correlation with cholesterol as well as with triglyceride. The correlation

Table II Mean \pm s.d. values for cholesterol, triglyceride and Apo-AI in different quintiles of $\mathrm{COHb} \%$. $(n=1035$ for cholesterol and triglyceride; for Apo-AI, $n=400$ ).

\begin{tabular}{|c|c|c|c|c|c|c|}
\hline & All & - & $\begin{array}{c}\mathrm{COHb} \% \\
0.52 \\
-\overline{0.61}\end{array}$ & $\begin{array}{l}0.62 \\
\overline{1.21}\end{array}$ & $\begin{array}{l}1.22 \\
2.02\end{array}$ & $\begin{array}{l}2.03 \\
-\end{array}$ \\
\hline $\begin{array}{l}\text { Cholesterol } \\
\text { Triglyceride } \\
\text { Apo-AI }\end{array}$ & $\begin{array}{c}5.81 \pm 1.08 \\
1.76 \pm 1.03 \\
116.15 \pm 21.08\end{array}$ & $\begin{array}{c}5.74 \pm 1.00 \\
1.69 \pm 0.91 \\
117.18 \pm 20.28\end{array}$ & $\begin{array}{c}5.71 \pm 1.04 \\
1.58 \pm 0.82 \\
116.14 \pm 21.59\end{array}$ & $\begin{array}{c}5.74 \pm 1.07 \\
1.85 \pm 1.14 \\
116.55 \pm 18.03\end{array}$ & $\begin{array}{c}5.97 \pm 1.17 \\
1.83 \pm 1.09 \\
115.25 \pm 17.52\end{array}$ & $\begin{array}{c}5.88 \pm 1.12 \\
1.84 \pm 1.14 \\
115.63 \pm 19.88\end{array}$ \\
\hline
\end{tabular}

F-values for variances between quintiles: cholesterol: 2.27 ; triglyceride: $2.82(P<0.05)$, Apo-AI; 0.1 . 
Table III Mean \pm s.d. values for cholesterol, triglyceride and Apo-AI in different quintiles of GGT. ( $n=1035$ for cholesterol and triglyceride; for Apo-AI, $n=400$ ).

\begin{tabular}{lccccc}
\hline & & & $G G T$ & & \\
& & 0.20 & 0.24 & 0.31 & 0.45 \\
& 0.19 & 0.23 & 0.30 & -.44 & \\
\hline Cholesterol & $5.54 \pm 0.98$ & $5.56 \pm 0.97$ & $5.80 \pm 1.01$ & $5.95 \pm 1.06$ & $6.19 \pm 1.24$ \\
Triglyceride & $1.41 \pm 0.66$ & $1.55 \pm 0.81$ & $1.67 \pm 0.83$ & $1.86 \pm 1.10$ & $2.29 \pm 1.38$ \\
Apo-AI & $113.97 \pm 17.87$ & $114.28 \pm 15.44$ & $117.22 \pm 21.55$ & $111.34 \pm 18.02$ & $123.89 \pm 27.97$
\end{tabular}

F-values for variances between quintiles: cholesterol: $13.67(P<0.001)$; triglyceride: $23.8(P<0.001)$; Apo-AI: $4.4(P<0.01)$.

coefficient between GGT and cholesterol was 0.08 $(P<0.05)$, between $\mathrm{A} / \mathrm{I}$ weight and cholesterol 0.13 $(P<0.001)$ and between GGT and cholesterol 0.11 $(P<0.001)$. The correlation coefficient between triglyceride and $\mathrm{COHb} \%$ was $0.1(P<0.01)$, between A/I weight and triglyceride $0.29(P<0.001)$ and between GGT and triglyceride $0.23(P<0.001)$. A/I weight was negatively correlated to Apo-AI, $\mathrm{r}=-0.23(P<0.001)$ whereas GGT was found to have a positive correlation with Apo-AI $\mathrm{r}=0.29$ $(P<0.001)$. When taking $\mathrm{COHb} \%$, GGT and $\mathrm{A} / \mathrm{I}$ weight into account the correlation to cholesterol was $0.2(P<0.05)$, to triglyceride $0.4(P<0.01)$ and ApoAI $0.32(P<0.05)$. Four per cent of the cholesterol variability, $16 \%$ of the triglyceride variability and about $16 \%$ of the variability in Apo-AI could be explained by these three factors all taken together. The distributions of $\mathrm{COHb} \%$, GGT and triglyceride were all positively skew. For this reason we log transformed these variables and again did the correlation analysis. This did not, however, significantly change the correlation coefficients given.

The one-way analysis of variance is illustrated in Table II, III and IV. The statistically significant correlations between $\mathrm{COHb} \%$ and cholesterol and triglycerides respectively turned out to be clinically insignificant when comparing mean values of these lipids in different quintiles of $\mathrm{COHb} \%$. GGT and body weight, on the other hand, both seemed to have a clinically significant influence on blood lipids. Mean cholesterol values differed about $10 \%$ when comparing the lowest and highest quintiles of GGT and A/I weight, respectively. Serum triglyceride levels in corresponding quintiles differed by about $60 \%$. Mean ApoAI was in the top quintile of GGT, $10 \%$ higher than in the lowest quintile. In the top quintile of $\mathrm{A} / \mathrm{I}$ weight Apo-AI was $8 \%$ lower than in the two lowest quintiles.

\section{Discussion}

In our study we used both analysis of variance and linear regression to assess how much of the variability in blood lipids can be accounted for by smoking, drinking and body weight. Although all three factors were found to have significant correlation to cholesterol, triglyceride, A/I-weight and GGT to Apo-AI as well, the comparison of mean lipid values in different quintiles of GGT, A/I weight and $\mathrm{COHb} \%$ revealed that some of these statistically significant correlations were presumably without biological significance. Associations based on the analysis of variance and linear regression are not comparable, however. When comparing mean lipid values in different quintiles of

Table IV Mean \pm s.d. values for cholesterol, triglyceride and Apo-AI in different quintiles of A/I weight. ( $n=1035$ for cholesterol and triglyceride; for Apo-AI, $n=400$ ).

\begin{tabular}{|c|c|c|c|c|c|}
\hline & - & $\frac{0.95}{1.03}$ & $\begin{array}{c}\text { A/I weight } \\
1.04 \\
-1.10\end{array}$ & $\frac{1.11}{1.19}$ & $\begin{array}{r}1.20 \\
-\end{array}$ \\
\hline $\begin{array}{l}\text { Cholesterol } \\
\text { Triglyceride } \\
\text { Apo-AI }\end{array}$ & $\begin{array}{c}5.51 \pm 0.08 \\
1.37 \pm 0.84 \\
121.67 \pm 26.06\end{array}$ & $\begin{array}{c}5.82 \pm 1.21 \\
1.61 \pm 0.96 \\
121.92 \pm 26.68\end{array}$ & $\begin{array}{c}5.88 \pm 1.11 \\
1.75 \pm 0.88 \\
111.16 \pm 13.37\end{array}$ & $\begin{array}{c}5.82 \pm 1.04 \\
1.76 \pm 0.88 \\
113.18 \pm 16.72\end{array}$ & $\begin{array}{c}6.04 \pm 1.11 \\
2.32 \pm 1.31 \\
112.18 \pm 15.72\end{array}$ \\
\hline
\end{tabular}

F-values for variances between quintiles: cholesterol: $6.58(P<0.01)$; triglyceride: $25.2(P<0.001)$; Apo-AI: $5.41(P<0.01)$ 
GGT, for instance, no adjustment was made for differences in smoking habits and/or body weight between groups whereas the partial correlation coefficients between GGT and lipids were calculated after adjustment for the influence of $\mathrm{COHb} \%$ and $\mathrm{A} / \mathrm{I}$ weight.

Increased levels of LDL in combination with reduced levels of HDL has been considered the lipid profile that is most strongly associated with increased risk of coronary heart disease (Gordon et al., 1977). In the present study this high risk profile would be reflected by increased levels of cholesterol and triglyceride, the major lipid components of LDL, in combination with reduced levels of Apo-AI - the major component of HDL. Smoking was in the present study found to have negligible long-term effect on blood lipids. GGT and body weight, on the other hand, had both, independent of each other, a sig-

\section{References}

ALBRINK, M.H. \& MEIGS, I.W. (1964). Interrelationships between skinfold thickness, serum lipids and blood sugar in normal man. American Journal of Clinical Nutrition, 15, 255.

BIOMEDICAL COMPUTER PROGRAM (1981). Statistical Software. University of California Press, Berkeley, Los Angeles, London.

BROWN, M.B. \& FORSYTHE, A.B. (1974). Robust tests for the equality of variances. Journal of the American Statistical Association, 69, 364.

COLLISON, H.A., RODKEY, F.L. \& O'NEAL, J.D. (1968). Determination of carbon monoxide in blood by gas chromatography. Clinical Chemistry, 14, 162.

DALES, L.G., FRIEDMAN, G.D., SIEGLAUB, A.B. \& SELTZER, C.C. (1974). Cigarette smoking and serum chemistry tests. Journal of Chronic Diseases, 27, 293.

DANIELSSON, B., EKMAN, R., FEX, G., JOHANSSON, B.G., KRISTENSSON, NILSSON, H., EHLE \& WADSTEIN, J. (1978). Changes in plasma high density lipoproteins during and after abuse. Scandinavian Journal of Clinical and Laboratory Investigation, 38, 113.

GOLDBOURT, U. \& MEDALIE, J.H. (1977). Characteristics of smokers, non-smokers and ex-smokers among 10,000 adult males in Israel. American Journal of Epidemiology, 105, 75 .

GORDON, T., CASTELLI, W.P., HJORTLAND, M.C., KANNEL, W.B. \& DAWBER, T.R. (1977). High density lipoprotein as a protective factor against coronary heart disease. The Framingham study. American Journal of Medicine, 62, 707. nificant influence on both cholesterol, triglyceride and Apo-AI. Serum triglyceride levels, for instance, in the lowest and highest quintiles of GGT had a $60 \%$ difference. When taking all three factors into account we were able to explain $4 \%$ of the cholesterol variability, $16 \%$ of the triglyceride variability and about $10 \%$ of the variability in Apo-AI. Of course one might argue that the influence of these three life style factors on blood lipids as assessed by the correlation coefficient is fairly small and of questionable importance for the individual patient. From the perspective of public health, however, the magnitude of the observed correlations is still of interest and suggests that the lipid-lowering effect associated with mass intervention on drinking habits and body weight can be expected to have measurable effects on the incidence of arteriosclerotic disease in the population.

JANZON, L., LINDELL, S.E., TRELL, E. \& LARME, P. (1981) Smoking habits and carboxyhaemoglobin. A cross sectional study of an urban population of middle-aged men. Journal of Epidemiology and Community Health, 35, 271.

LAURELL, C.B. (1965). Antigen-antibody crossed electrophoresis. Biochemistry, 10, 358.

LINDEBERG, W., NATVIG, H., RYGH, A. \& SVENDSEN, K尺 (1956). Height and weight measurements in adult men an women. Tidsskrift for den Norsk Laegeforening, 76, 361 . OSTRANDER, L.D., LAMPHIEAR, M.A., BLOCK, W.D. JOHNSON, B.C., RAVANSCROFT, C. \& EPSTEIN, F.H (1974). Relationship of serum lipid concentrations to alcohol consumption. Archives of Internal Medicine, 134, 451.

PETERSON, B., KRISTENSON, H., STERNBY, N.H., TRELL, E., FEX, G. \& HOOD, B. (1980). Alcohol consumption and premature death in middle aged men. British Medical Journal, 280, 1403.

ROESCHLAV, P., BERT, E. \& GRUBER, W. (1974). Enzymatische Bestimmung des Gesamt-Cholesterins in Serum. Zeitschrift für Klinische Chemie und Klinische Biochemie, 12, 226.

WAHLEFELDT, A.W. (1974). Triglyceride determination after enzymatic hydrolysis. In Methods in Enzymatic Analysis, 22nd ed. pp 1831. H.V. Bergmeger (Ed). Academic Press, New York.

WHITEHEAD, T.P.. CLARKE, C.A. \& WHITFIELD, A.G.W (1978). Biochemical and haematological markers of alcohol intake. Lancet, i, 978. 